\title{
ELABORAÇÃO DE SORVETE COM ADIÇÃO DE SORO DE QUEIJO EM PÓ
}

\author{
Gabriela Vettorello ${ }^{1}$, Aline Botasssoli Dalcorso² ${ }^{2}$ Jonas Betti ${ }^{3}$, \\ Grasciele Tamara Kemerich ${ }^{4}$, Eniz Conceição Oliveira ${ }^{5}$
}

\begin{abstract}
Resumo: O sorvete é um produto alimentício classificado pela ANVISA (Agência Nacional de Vigilância Sanitária) como um gelado comestível, obtido a partir da emulsão de gorduras e proteínas. É considerado um dos alimentos mais consumidos no mundo, tratando-se de um mercado em expansão e que carece de novas formulações para elaboração de produtos diferenciados. O presente trabalho teve como objetivo desenvolver três formulações de sorvete com adição de soro de queijo em pó, em substituição ao leite UHT (Ultra High Temperature) nas concentrações de 0\%, 50\% e $100 \%$, avaliando suas composições físico-químicas e características sensoriais. A formulação que apresentou maior aceitabilidade pela análise sensorial e resultados nas análises físico-químicas de proteína, gordura e sólidos totais compatíveis com os valores descritos na legislação nacional vigente e na literatura consultada foi a formulação B (50\% soro de queijo). O soro de queijo substituindo $50 \%$ do leite pode ser uma iniciativa aceitável para a indústria de gelados comestíveis.
\end{abstract}

Palavras-chave: Soro de queijo. Sorvete. Reaproveitamento.

\section{INTRODUÇÃO}

As evidências do surgimento do sorvete datam do período medieval pelos europeus, obtido através de alterações feitas em bebidas geladas, considerado um comestível gelado (MARSHALL; ARBUCKLE, 1996). Caracterizado um

1 Graduanda do Curso de Química Industrial da Universidade do Vale do Taquari - UNIVATES.

2 Graduanda do Curso de Química Industrial da Universidade do Vale do Taquari - UNIVATES.

3 Graduando do Curso de Química Industrial da Universidade do Vale do Taquari - UNIVATES.

4 Mestranda do Programa de Pós-Graduação em Biotecnologia da Universidade do Vale do Taquari - UNIVATES.

5 Doutorado na Universidade Federal do Rio Grande do Sul. Professora titular na Universidade do Vale do Taquari - UNIVATES. 
alimento nutritivo, saudável e de baixo custo, o sorvete pode ser consumido por pessoas de todas as idades, sexo e condição social, garantindo espaço de destaque no mercado de consumo em todos os países. Somente no ano de 2011 a produção nacional atingiu a marca de 1.167 milhões de litros (SEBRAE, 2011).

O sorvete é um produto alimentício classificado pela ANVISA (BRASIL, 2003) como um gelado comestível, obtido a partir da emulsão de gorduras e proteínas, onde se podem adicionar outros ingredientes, desde que os mesmos não descaracterizem o produto, garantam sua conservação em estados totais ou parciais de congelamento, armazenamento, transporte e respectivo consumo.

Para atender as expectativas dos consumidores, os fabricantes vêm substituindo ingredientes calóricos como, por exemplo, similares de gordura e açúcar. Partindo-se dessa iniciativa, estas alternativas podem se voltar para o reaproveitamento de subprodutos de demais indústrias alimentícias, como é o caso do soro de queijo, que pode ser adicionado ao leite como matéria-prima, agregando-se assim outros valores nutritivos e com custo inferior ao tradicional (MALANDRIN; PAISANO; COSTA, 2001). O soro gerado na produção de queijos representa 80 a $90 \%$ do volume total de leite que entra na indústria, e possui em sua composição um valor equivalente a 50\% dos nutrientes do leite, sendo constituído por proteínas solúveis, lactose, vitaminas e minerais (MAGANHA, 2006) que apresentam propriedades nutricionais benéficas à saúde (PRUDENCIO, 2006). Do ponto de vista funcional, as proteínas do soro apresentam propriedades emulsificantes ( $\alpha$-lactalbumina), espumante e gelificante, devido principalmente a flexibilidade e natureza anfifílica das $\beta$-lactoglobulinas (PRUDENCIO, 2006), a lactoferrina e a lactoperoxidase apresentam propriedades bacteriostáticas (ANTUNES, 2003).

Para o meio ambiente o soro descartado sem o devido tratamento é considerado poluente ambiental, por elevar a carga orgânica do local, com uma demanda bioquímica de oxigênio (DBO) de 30.000 a $50.000 \mathrm{mg} / \mathrm{L}$ e uma demanda química de oxigênio (DQO) de 50.000 a $80.000 \mathrm{mg} / \mathrm{L}$ (COSTA et al., 2014). A busca por alternativas de utilizar este soro vem crescendo a cada ano devido ao aumento na fabricação de queijos e como consequência o alto volume de resíduos gerados (PRUDENCIO, 2006). Atualmente, o soro deixou de ser considerado resíduo e passou a ser tratado como subproduto na fabricação de outros produtos, e possibilitou que seu beneficiamento tenha grande importância econômica (MAGANHA, 2006).

Com base nestes aspectos, o objetivo do presente trabalho foi desenvolver um sorvete e avaliar as suas características físico-químicas e sensoriais tendo como um dos ingredientes principais o soro de queijo em substituição parcial a utilização de leite integral em sua formulação, visando criar um produto inovador através do reaproveitamento de um subproduto industrial prejudicial ao meio ambiente, analisando sua composição físico-química e aceitação sensorial. 


\section{METODOLOGIA}

\subsection{Elaboração do produto}

Desenvolveram-se três formulações (A, B e C), de sorvete de morango com diferentes concentrações de soro de queijo em pó. A formulação A foi utilizada como amostra controle, adicionando-se apenas leite UHT (ultra high temperature - ultrapasteurizado) integral, sem substituição por soro. A reconstituição do soro de queijo em pó foi realizada através da dissolução de 75,8 gramas de soro em $1000 \mathrm{~mL}$ de água. A formulação B foi elaborada utilizando-se $50 \%$ de leite UHT integral e $50 \%$ de soro de queijo reconstituído, obtida como amostra intermediária, enquanto que a formulação C utilizou $100 \%$ soro reconstituído em substituição ao volume de leite UHT integral. Todos os ingredientes utilizados em cada formulação estão apresentados na Tabela 1.

Tabela 1: Formulação de sorvete de morango com soro de queijo em pó

\begin{tabular}{l|c|c|c}
\hline Ingredientes & Formulação A & Formulação B & Formulação C \\
\hline Leite UHT Integral $(\mathrm{mL})$ & 600 & 300 & 0,00 \\
\hline Soro de Queijo Reconstituído $(\mathrm{mL})$ & 0,00 & 300 & 600 \\
\hline Morango $(\mathrm{g})$ & 150 & 150 & 150 \\
\hline Açúcar Refinado $(\mathrm{g})$ & 112 & 112 & 112 \\
\hline Creme de Leite $(\mathrm{g})$ & 65 & 65 & 65 \\
\hline Leite em Pó Integral $(\mathrm{g})$ & 60 & 60 & 60 \\
\hline Liga neutra (g) & 5 & 5 & 5 \\
\hline Emustab (g) & 5 & 5 & 5 \\
\hline
\end{tabular}

Fonte: Dos Autores

Os sorvetes foram produzidos no Laboratório de Cárneos e Lácteos (Universidade do Vale do Taquari - Univates, Lajeado/RS). O desenvolvimento do produto foi realizado primeiramente pesando-se os ingredientes, após homogeneizando-os em liquidificador por 3 minutos. A mistura permaneceu em repouso no congelador por aproximadamente 24 horas. Após este período, adicionou-se o emustab da marca Selecta e com a utilização de uma batedeira, o produto foi homogeneizado por 5 minutos. Armazenou-se em congelador até o momento do consumo.

\subsection{Determinações físico-químicas}

As análises físico-química foram realizadas em duplicata, contemplando os parâmetros de sólidos totais, realizado em estufa a $105^{\circ} \mathrm{C}$ (marca DeLeo, modelo A6AFD), matéria mineral em forno mufla a $550^{\circ} \mathrm{C}$ (marca Marconi, modelo MA 385/2), $\mathrm{pH}$ por método potenciométrico (marca Metrohm, modelo $827 \mathrm{pH}$ lab), teor de proteínas por meio da determinação do teor de nitrogênio 
total pelo método de Macro-Kjeldahl (marca Marconi), de acordo com as Normas Analíticas do Instituto Adolfo Lutz (INSTITUTO ADOLFO LUTZ, 2008), teor de gordura pelo método de Mojonier. A atividade de água (AW do inglês activity water) foi determinada utilizando o equipamento AquaLab Life Decagon e o teor de carboidratos totais foi calculado pela diferença de 100 gramas de amostra e a soma total dos valores encontrados de umidade, matéria mineral, proteína e lipídios (CECCHI, 2003).

\subsection{Análise sensorial}

A análise sensorial é utilizada para medir, analisar e interpretar características de alimentos e outros produtos na forma como são percebidas pela visão, olfato, gosto, tato e audição. A análise sensorial de escala hedônica é demarcada no extremo esquerdo como "Desgostei extremamente" e no direito como "gostei extremamente". A vantagem é ausência de valor numérico somado a um número limitado de palavras, que minimizam a tendências dos consumidores em evitar ou preferir determinados números ou expressões (MINIM, 2013).

A análise sensorial foi realizada com 50 provadores não treinados. As amostras foram codificadas com números de três dígitos aleatórios e questionadas segundo seu aspecto de sabor, odor, textura e impressão global numa escala hedônica de nove pontos, variando de gostei muitíssimo até desgostei muitíssimo. Avaliou-se também a intenção de compra, variando de 1 "certamente não compraria" até 5 "certamente compraria". Para o índice de aceitabilidade (IA) das amostras foi adotada a expressão IA $(\%)=\mathrm{A} \times 100 / \mathrm{B}$, na qual A é a média das notas do produto e B a nota máxima (MINIM, 2006).

\section{RESULTADOS E DISCUSSÕES}

Na Tabela 2 são apresentados os resultados das análises físico-químicas das formulações do sorvete de morango com substituição parcial do conteúdo de leite integral por soro de queijo em pó.

Tabela 2. Composição centesimal das formulações de sorvete com soro de queijo

\begin{tabular}{l|c|c|c}
\hline Composição centesimal & Formulação A & Formulação B & Formulação C \\
\hline Sólidos Totais (\%) & 25,85 & 22,56 & 21,14 \\
\hline Proteína (\%) & 3,59 & 2,91 & 2,36 \\
\hline Gordura (\%) & 4,43 & 3,48 & 2,67 \\
\hline Aw & 0,920 & 0,911 & 0,910 \\
\hline Cinzas (\%) & 0,90 & 0,79 & 0,73 \\
\hline pH & 6,14 & 6,08 & 6,15 \\
\hline Carboidratos (\%) & 16,93 & 15,38 & 15,38 \\
\hline
\end{tabular}

Fonte: Dos Autores. 
Segundo os estudos realizados por Almeida, Bonassi e Roça (2001) os valores de gordura diminuíram à medida que aumentou a concentração de soro de queijo, estes resultados estão de acordo com os valores obtidos nas formulações do presente trabalho, onde se observou o mesmo comportamento, com valores de $4,43 \%$ para a formulação A e $2,67 \%$ para a formulação com a maior quantidade de soro (formulação C). Este resultado é explicado devido aos valores encontrados para a gordura do leite integral, que é de no mínimo 3\% segundo a Instrução Normativa 62 (BRASIL, 2011), enquanto que o soro apresenta uma composição aproximada de $0,5 \%$ segundo Antunes (2003).

Os valores encontrados para sólidos totais variaram de $25,85 \%$ para a formulação A a 21,14\% para a formulação C. Estes resultados vão de encontro aos valores teóricos de composição da matéria-prima, uma vez que a Instrução Normativa 62 (BRASIL, 2011) estabelece um mínimo de 8,4 g/100g para sólidos totais como extrato seco desengordurado no leite UHT integral (formulação A) e Antunes (2003) apresenta uma composição aproximada de 6,5\% de sólidos totais no soro, explicando o valor menor encontrado para a formulação C.

Para a proteína bruta os resultados variaram de 3,59\% para a formulação A, 2,91\% para a formulação B e 2,36\% para a formulação C. O teor encontrado na formulação A está de acordo com a Instrução Normativa 62 (BRASIL, 2011), que é de no mínimo de $2,9 \%$ de proteína para o leite integral, utilizado nesta formulação. Antunes (2003) apresenta um valor de 0,8\% de proteína para o soro líquido, justificando a diminuição do valor de proteína nas formulações que apresentam substituição de leite integral (parcial ou total) por soro em pó reconstituído em relação a formulação onde não houve substituição (formulação A). De acordo com a ANVISA (1999) em seu Regulamento Técnico para Fixação de Identidade e Qualidade de Gelados Comestíveis, somente a formulação C ficou abaixo do limite de $2,5 \mathrm{~g} / 100 \mathrm{~g}$, devido à substituição total do leite integral na formulação.

Para a avaliação sensorial dos sorvetes avaliamos a aceitação do produto pelos consumidores, relacionando com os aspectos de cor, odor, sabor, textura e impressão global. O mesmo deu-se em uma escala de avaliação de 1 a 9, correspondente a desgostei muitíssimo a gostei muitíssimo. Conforme apresentado na Figura 1, a formulação que utiliza 50\% soro de queijo em substituição ao leite UHT obteve maior aceitação em todos os aspectos, comparando com as formulações 100\% UHT (Formulação A) e $100 \%$ soro (Formulação C).

Alguns aspectos apresentados durante a análise sensorial foram prejudiciais, devido a amostra estar sendo submetida a uma temperatura inadequada, por um período prolongado de tempo, causando alterações na qualidade visual da mesma. Estas perdas podem ser visualizadas na Figura 1 para os atributos textura e aparência. 
Figura 1 - Resultado da aceitação sensorial das formulações de sorvete com diferentes concentrações de soro de queijo

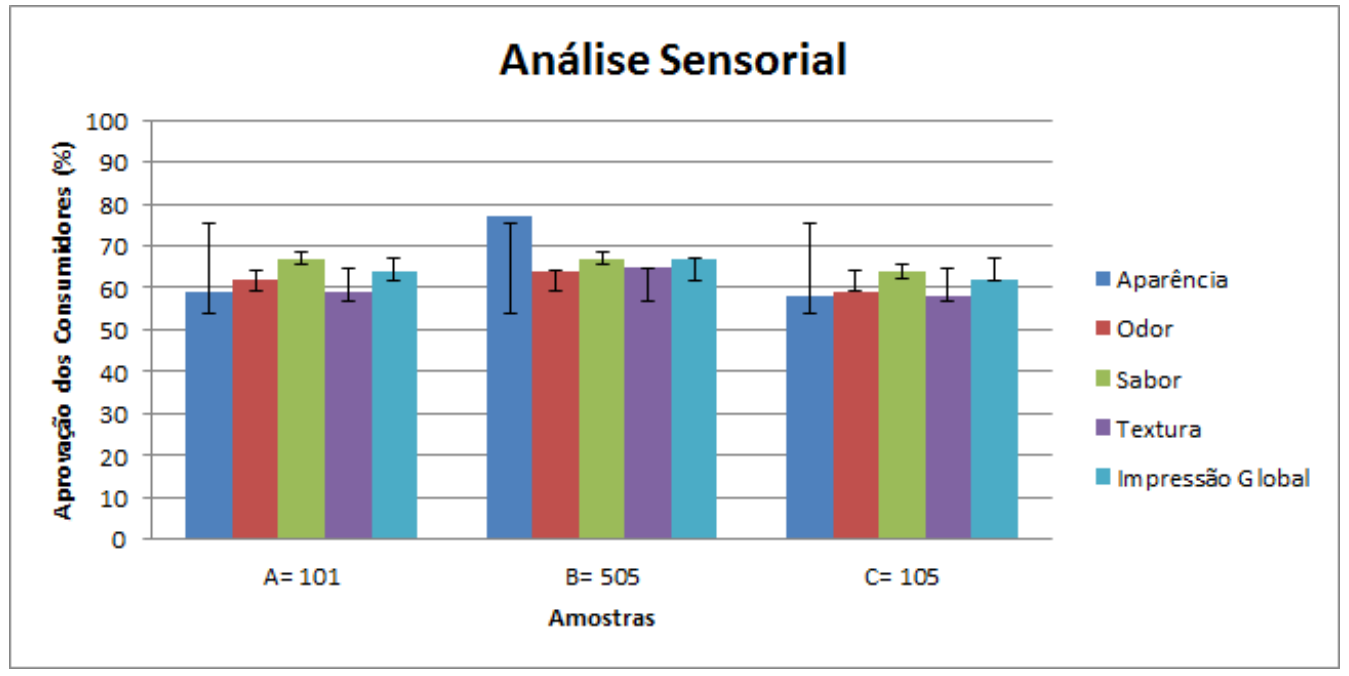

Fonte: dos autores.

Os resultados da análise sensorial para as formulações A, B e C demonstrados em um gráfico de barras em uma escala de certamente não compraria a certamente compraria estão apresentados na Figura 2. A partir da mesma percebe-se maior aceitabilidade do consumidor, para possivelmente compraria, para a amostra B, compatível com os resultados apresentados na Figura 1.

Já para as amostras A e C, índices de que o produto possivelmente seria comprado possuem valores próximos a $30 \%$, porém são acompanhados pelo resultado de talvez compraria/talvez não compraria, demonstrando a incerteza do consumidor perante a real aquisição do produto.

Entretanto, os resultados dos demais aspectos analisados evidenciam a necessidade de melhorias no produto para possível comercialização. Pois, perante a análise sensorial a impressão global nos mostra um índice de $69 \%$ de aceitação dos consumidores, algo que afeta diretamente na intenção de compra, onde a incerteza de adquirir ou não nosso produto deu-se de forma elevada. 
Figura 2. Gráfico de barras para intenção de compra das formulações de sorvete com diferentes concentrações de soro de queijo

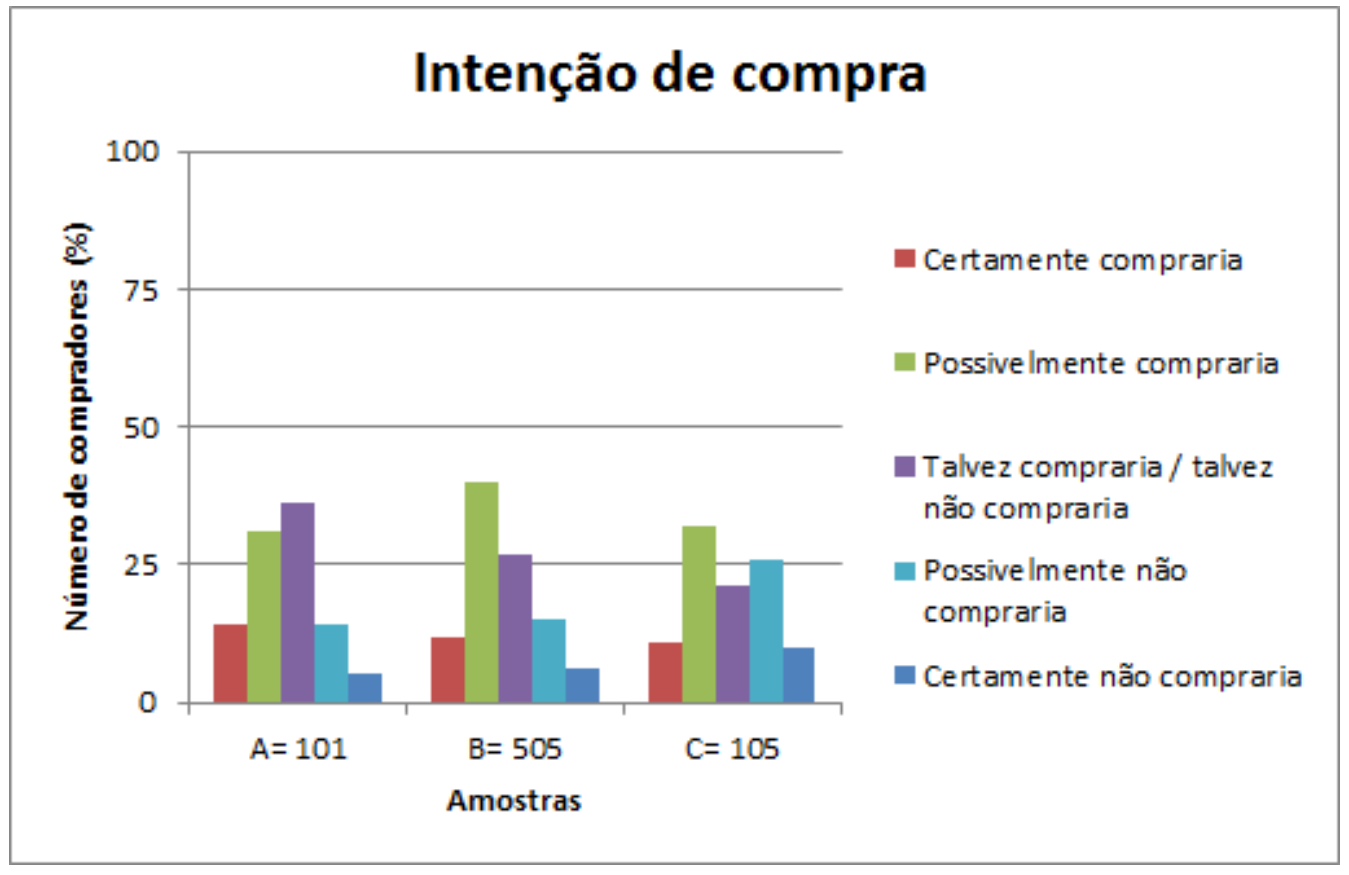

Fonte: dos autores.

Comparar os resultados da avaliação sensorial com os obtidos em outros trabalhos já publicados.

Identifica-se através dos resultados da análise sensorial que a formulação B obteve maior aceitação, comprovando que a substituição parcial do leite UHT por soro de queijo reconstituído é uma opção viável para o reaproveitamento deste resíduo industrial. Algumas características organolépticas ainda podem ser exploradas com o acréscimo de aditivos que confiram melhores aspectos sensoriais.

\section{CONCLUSÃO}

Concluiu-se fundamentado nos estudos e valores apresentados, que a formulação B obteve resultados nas análises físico-químicas de proteína, gordura e sólidos totais compatíveis com os valores descritos na legislação nacional vigente e na literatura consultada, e de intenção de compra superiores aos das demais formulações. Porém, é necessário ajustar a formulação do sorvete para uma maior aceitabilidade dos consumidores. A adição do soro de queijo em sorvete possibilita a utilização desse subproduto em um alimento amplamente consumido pela população. 


\section{REFERÊNCIAS}

ALMEIDA, K.E.; BONASSI, I.A. e ROÇA, R.O.Características físicas e químicas de bebidas lácteas fermentadas e preparadas com soro de queijo minas frescal. Ciência e Tecnologia de Alimentos., v.21, p.187-192. São Paulo, 2001. Disponível em: <http:/ / www.scielo.br/scielo.php?script=sci_arttext\&pid=S0101-20612001000200012\&lng=pt> Acesso em: 08 nov 2017

ANTUNES, Aloísio José. Funcionalidade de proteínas do soro de leite bovino. Barueri: Manole, 2003.

BRASIL. Agência Nacional de Vigilância Sanitária. Resolução RDC nº 267, de 25 de dezembro de 2003. Regulamento Técnico de Boas Práticas de Fabricação para Estabelecimentos Industrializadores de Gelados Comestíveis e a Lista de Verificação das Boas Práticas de Fabricação para Estabelecimentos Industrializadores de Gelados Comestíveis. Disponível em <https://goo.gl/5qg9Do>. Acesso em: 08 nov 2017.

BRASIL. Ministério da agricultura, pecuária e abastecimento. Instrução Normativa n 62, de 29 de dezembro de 2011. Regulamento Técnico de Produção, Identidade e Qualidade do Leite tipo A, o Regulamento Técnico de Identidade e Qualidade de Leite Cru Refrigerado, o Regulamento Técnico de Identidade e Qualidade de Leite Pasteurizado e o Regulamento Técnico da Coleta de Leite Cru Refrigerado e seu Transporte a Granel. Disponível em: <http:/ / www.apcbrh.com.br/files/IN62.pdf>. Acesso em: 08 nov 2017.

CECCHI, H. M. Fundamentos teóricos e práticos em análise de alimentos. Editora da UNICAMP: $2^{\circ}$ Ed. rev.- Campinas, SP, editora da UNICAMP, 207p., 2003.

COSTA et al. Soro de leite e os danos causados ao meio ambiente. São Paulo, 2014. Disponível em: http:/ /www2.unifesp.br/home_diadema/eba2014/br/resumos / R0038-1.PDF. Acesso em 08 nov, 2017.

INSTITUTO ADOLFO LUTZ. Métodos físico-químicos para análise de alimentos. $4^{\mathrm{a}}$ edição. $1^{\text {a }}$ edição digital. São Paulo, 2008. Disponível em: <http: / / wp.ufpel.edu.br / nutricaobromatologia/files/2013/07/NormasADOLFOLUTZ.pdf>. Acesso em: 01 nov 2017.

MAGANHA, M.F.B. Guia técnico ambiental da indústria de produtos lácteos. São Paulo: CETESB, 2006. p.95. Disponível em: <https:/ / www2.cead.ufv.br/sgal/files/ apoio/saibaMais/saibaMais5.pdf>. Acesso em 08 nov, 2017.

MALANDRIN, R.; PAISANO, M.; COSTA, O. Sorvetes: um mercado sempre pronto para crescer com inovações. Food Ingredients, n. 15, p. 42-48, nov.-dez. 2001.

MARSHALL, R. T.; ARBUCKLE, W.S. Ice cream. 5th ed. New York: International Thomson Publ., 1996. 349p.

MINIM, V. P. R. Análise sensorial: estudos com consumidores. Viçosa: UFV, 2006. $403225 \mathrm{p}$. 
MINIM, V. P. R. (Ed). Análise sensorial: estudos com consumidores. 3. ed. Viçosa: UFV, 2013.

PRUDENCIO, I. D. Propriedades físicas de queijo petit suisse elaborado com retentado de soro de queijo e estabilidade de antocianinas e betalaínas adicionadas. Dissertação de Pós-graduação em Ciência dos Alimentos da Universidade Federal de Santa Catarina. Florianópolis, SC. Disponível em: <http:/ /livros01.livrosgratis.com. br/cp002188.pdf> Acesso em: 04. nov. 2017.

SEBRAE. Ideias de Negócio - Como montar uma sorveteria. 2011. Disponível em<externalfile:drive-949ebf1137bbb5750c7fb94023ca5abff4941cc7/root/Sorveteria. pdf $>$. Acesso em 22 nov, 2017. 